\title{
Nikolaos Chrissidis
}

An Academy at the Court of the Tsars: Greek Scholars and Jesuit Education in Early

Modern Russia. DeKalb, Ill.: Northern Illinois University Press, 2016. Pp. 384.

$\mathrm{Pb}, \$ 55$.

Discussions of education and, more broadly, cultural change in seventeenthand eighteenth-century Russia have long seemed to begin and end in the same place. It is assumed that a basically monolithic, static, autarkic Orthodox Russia stood opposed to a wide range of Western cultural developments ranging from the Catholic Reformation to the emergence of print culture, and that "Westernization" was a question of the latter being more or less forcibly being inducted into the former. Although few now hold Peter the Great's reforms to be wholly unprecedented, his seventeenth-century antecedents are typically framed as driven by a Polonized, Catholic-influenced court elite; even the Orthodox Ukrainian churchmen who were at the forefront of certain aspects of these reforms were able to play this role because of their roots in the confessionalization struggles of early modern Poland-Lithuania. In other words, the Orthodox world held Russia back, while the Catholic and Protestant worlds pulled it reluctantly forward.

Nikolaos Chrissidis's An Academy at the Court of the Tsars is an insightful, well-researched, and persuasive refutation of this narrative. It is a story of two brothers, Ioannikios and Sophronios Leichoudes, tracing their travels from the Jesuit-influenced educational institutions of seventeenth-century Italy to the increasingly dynamic world of the Muscovite capital where they founded a Slavic-Latin-Greek Academy (est. 1687) that exists, in some form, to this day. The Leichoudes' school was patterned directly on a Jesuit college. As the first Western-style formal educational institution in all of Russia it produced dozens of successful graduates, who would soon come to staff Peter's reformed institutions. Its legacy thus proved far more enduring than the careers of the Leichoudes brothers themselves. In 1694, they had first come under criticism from other members of the Muscovite Greek community; they were then removed from their Academy posts after trying to defend Ioannikios's son, who was keeping a lover in the Academy building. The full story of their lives in the 1690 and 1700 s has hitherto been seldom and inaccurately told, and remedying this is one of Chrissidis's welcome contributions.

The book's opening chapters, which place the peripatetic Leichoudes brothers in the context of an Orthodox world that outside of Russia was turbulent, hybrid, and remarkably open to outside influences, are especially useful for proving Chrissidis's point. Historians of seventeenth-century Russia, long accustomed to seeing the Orthodox Balkans as a kind of quiescent cultural 
hinterland for Russian Orthodoxy, prevented by the Ottoman yoke from developing independently, will learn much here. Far from being compelled by the irresistible appeal of the world's only Orthodox state, the Leichoudes strongly felt the allure of Catholic Padua - where at least one of them received his university training - and picked Russia as an opportunistic career move. Subsequent chapters build on these insights as they provide careful genealogies of the Jesuit influence on the Leichoudes' pedagogical texts and follow the internecine struggles of the Greek community in Moscow.

It is all the more remarkable that an argument so conceptually robust is paired with such wide-ranging and thorough research. Chrissidis's command of Greek opens up a whole range of sources unavailable to most early modern Russian historians, who have usually relied on secondhand accounts of the Greek presence in Muscovy. Neither does he neglect manuscript sources in Russian, Latin, and Church Slavonic. Worth mentioning, too, is the book's awareness of and engagement with the work of contemporary Russia-based scholars like B.L. Fonkich and his successors; as the author rightly recognizes, they have pushed the field forward in ways that English-language historiography has not yet acknowledged.

In some ways, however, the very smallness of the Moscow Greeks' world proves a liability. The book gives little sense of their place in the much larger community of foreign teachers, specialists, and mercenaries in seventeenthcentury Moscow, which in the 168 os even included several Jesuits. The rigor and novelty of Chrissidis's readings is not in question-in a compelling chapter, he shows how the Leichoudes' curriculum did not in fact sideline Latin and Greek in favor of Slavic as prior scholars have believed - but their deep focus is rendered somewhat beside the point given the limited influence of these ideas. By the time of Ioannikios's death in 1717 , their echoes were so faint as to be almost imperceptible; parallels with the subsequent history of the Academy and later institutions like Peter's School of Mathematical and Navigational Sciences are misleading given the latter's secular, Dutch origins. Though perhaps unavoidable given the evanescence of the enlightened OrthodoxMuscovite conjuncture of the 1680 s, the book's narrow scope leaves one wishing that the author's prodigious talents were applied more ambitiously.

This minor complaint should serve only to underscore the importance of $A n$ Academy at the Court of the Tsars. For Russian historians it reveals a new side of late Muscovy. For scholars of Jesuit studies it provides a vivid demonstration of the influence and flexibility of the Jesuit educational model. For instance, Chrissidis uses his study of the Leichoudes' curriculum to trace the influence of Jesuit rhetorical manuals like Cipriano Soárez's De arte rhetorica (1568), 
through the Greek-language works of Gerasimos Vlachos, on Muscovite pedagogical practice. Similarly concrete textual and intellectual lineages are traced to Jesuit precedents in logic (Francisco de Toledo's Introductio in dialecticam, 1574) and cosmology (a variety of introductory Jesuit textbooks). Everywhere the pattern seems to be similar: Greeks working in the Jesuit-dominated world of the central Mediterranean drew on Jesuit, often Aristotelian, texts in formulating their pedagogy, and the Leichoudes were able to adapt the resulting works to a Russian context, along with the structural features of the Ratio studiorum more generally. In a wider early modern European context, Chrissidis's interpretation shows how doctrinal and religious difference could be more than just grounds for sectarian strife-it could also serve as a vector for fruitful hybridity and rejuvenating new influences. Though this may have worried the Leichoudes' religious patrons, seventeenth-century Russia was not a uniform bastion of traditional Orthodox teaching — and as Chrissidis shows us, that was a very good thing indeed.

\footnotetext{
Gregory Afinogenov

Harvard University

afinogen@fas.harvard.edu

DOI $10.1163 / 22141332-00402008-11$
} 